\title{
An epidemiological investigation of gastrointestinal parasites of small ruminants in Tangail, Bangladesh
}

\author{
Md. Atikur Rahman, Sharmin Shahid Labony, Anita Rani Dey and Mohammad Zahangir Alam
}

Department of Parasitology, Bangladesh Agricultural University, Mymensingh-2202, Bangladesh

ARTICLE INFO

Article history:

Received: 18 October 2017

Accepted: 17 December 2017

Keywords:

Gastrointestinal parasites,

Prevalence, Small ruminants,

Madhupur

Correspondence:

Mohammad Zahangir Alam

(mzalam@bau.edu.bd)

\begin{abstract}
Gastrointestinal (GI) parasitism is anegregious problem in small ruminant production system due to is impact on growth and associated cost of control measures. An epidemiological study was conducted to investigate the prevalence of gastrointestinal parasites of small ruminants from different areas of Madhupur, Tangail. The stool samples were collected from a total of 426 goats and sheep from study areas. Specimens were subjected to Stoll's ova counting technique and the overall prevalence of gastrointestinal parasitic infection was found $63.4 \%$. Overall prevalence of nematodes, cestodes, trematodes and protozoa was $52.11 \%, 2.11 \%, 36.62 \%$ and $10.33 \%$, respectively. The prevalence of parasites were variable with Fasciola spp. (8.45\%), Paramphistomum spp. (28.17\%), Monieziaspp. (2.11\%), Haemonchus spp. (31.22\%), Trichurisspp. (1.17\%), Oesophagostomum spp. (10.80\%), Strongyloides spp. (4.93\%), Trichostrongylus spp. (2.35\%), Bunostomum spp. (1.64\%), Eimeria spp. (24\%) and Balantidium spp. (6.34\%). Parasitic ova counts in male and female exhibited no significant variations ( $\mathrm{p}>0.05$ ) between them. The infection was significantly higher $(65.11 \%)$ in adult than in young $(58.09 \%)$. No significant $(\mathrm{p}>0.05)$ variation was observed in infection rates between goats $(64.09 \%)$ and sheep $(60.67 \%)$. Seasonal variation was found significant between rainy $(72.44 \%)$, winter $(56.72 \%)$ and summer $(61.82 \%)$ seasons. Animals with poor body conditions $(74.67 \%)$ were mostly affected compared to those with moderate $(62.38 \%)$ and good $(39.00 \%)$ body conditions. Further attempt is necessary for a structured surveillance and monitoring of GI parasites to formulate effective control measures.
\end{abstract}

\section{Introduction}

Small ruminants especially sheep and goats play an important role in the rural economy of Bangladesh and contribute to earnings of significant amount of foreign currency by exporting skins and other by-products (Kamaruddin, 2003). Goat rearing is becoming much exoteric in Bangladesh and nowadays special emphasis is also given to sheep production. In Bangladesh, parasitism has been contemplated as one of the important constraints of livestock production. Gastrointestinal parasites like helminths and protozoan are very common in sheep and goats. When heavy infections occur those parasites contribute to reduced milk and meat production (Murthy and Rao, 2014). Small ruminants under intensive and extensive production systems are extremely susceptible to the effects of wide range of helminths (Abede and Esayas, 2001). Helminth infestation lowers the immunity of the animals and render them susceptible to other pathogenic infections (Garedaghi et al., 2011).Previous reports suggested that amongst the disease of small ruminants, the parasitic diseases are of prime importance in Bangladesh (Rahman, 1975). He reported the death of as high as $25.0 \%$ kids and lambs and $43.5 \%$ adult goats due to GI parasites in both rural and farm condition. According to Choubisa and Jaroli (2013), parasitic infections were found in $82.97 \%$ and $55.42 \%$ goats and sheep, respectively in India. In another report, Mazid et al. (2006) reported that about $81.1 \%$ and $94.7 \%$ helminthiasis occurred in sheep and goats, respectively. Various risk factors related to host and environment play an important role in the onset of GI parasitic infections. Environmental factors include agro-ecological conditions, animal husbandry practices such as housing system, deworming intervals and pasture management; these largely determine the type, incidence and severity of various parasitic diseases (Badran et al., 2012). Other risk factors such as the host species, sex of the animal, age, body condition and breed/genotype, parasite species and intensity of the worm population, have an effect on the development of gastrointestinal parasitic infections (Tariq et al., 2010). Madhupur upazilla is very prospective for goat and sheep rearing due to its agroecological condition. Despite routine vaccination against major infectious diseases, small ruminants are still suffering from poor body condition state due to parasitism. However, there is limited information about the infection prevalence of GI parasites in small ruminants in the study area. Therefore, the present study was conducted to investigate the GI parasites prevalent in small ruminants in Madhupur upazila of Tangail district and identify associated risk factors such as age, sex, season, species and nutritional condition.

\section{Materials and Methods}

\section{Site profile and Study period}

The study areas were Madhupur upazilla under Tangail district. Samples were collected during the period from 
July 2015 to June 2016 . The study period covered rainy (July-October), winter (November-February) and summer season (March-June).

\section{Examination of samples}

A total of 426 fecal samples with epidemiological data from sheep (88) and goats (338)were gathered randomly from Madhupur upazilla, Tangail. Fecal samples were collected fresh in glass/plastic vials containing 10\% formalin and transported to the laboratory of the Department of Parasitology, Bangladesh Agricultural University (BAU). Two different age groups of small ruminants were selected, namely young (7-18 months) and adult (>18 months). Fecal samples were processed and tested under microscope through Stoll's ova dilution technique. At least, two smears were prepared from each sample for each test to identify the morphological characteristics of eggs, cyst, oocysts (Soulsby, 1982). Faecal egg counts were determined following the modified Stoll's ova counting technique (Soulsby, 1982).

\section{Identification of egg of helminths}

Eggs of different helminth worms were observed under a compound microscope $(10 \times$ objective) and identified by their characteristic morphological features (Soulsby, 1982).

\section{Statistical Analyses}

Statistical analyses were carried out by Statistical Package for Social Science (SPSS version 22.0, SPSS Inc., Illinois, USA) using $\mathrm{F}$ test. To identify the risk factors univariate analysis was performed.

\section{Results and Discussion}

\section{Overall prevalence of gastrointestinal parasites (GI)} in small ruminants

Our study revealed a variable prevalence of gastrointestinal parasitic infection in small ruminants of Madhupurupazila of Tangail District. The present study revealedthat $63.4 \%(270 / 426)$ small ruminants were infested with a numberof GI parasites, namely, Haemonchus spp., Oesophagostomum spp., Strongyloides spp., Trichostrongylus spp., Trichuris spp., Bunostomum spp., Moniezia spp., Fasciola gigantica, Paramphistomum spp., Eimeria spp., Balantidium coli (Fig. 1). These observations were found consistent with previous reports who recorded $65.6 \%, 63.3 \%$, 63.5\% prevalence in Bangladesh, Lahore and Islamabad, respectively (Ijaj et al., 2008; Gadahi et al., 2008; Hasan et al., 2011). However, this finding was comparatively lower than that reported by Poddar et al. (2017) who indicated $67.4 \%$ overall prevalence in Sherpur District of Bangladesh. Notable that in the study areas, pineapple are prevalent and this pineapple are sometime ingested by ruminants. While it is well known that pineapple contain anthelmintic compound (bromelain) (Domingues et al., 2013), this could be linked with lower prevalence of GI parasites in
Madhupur area of Tangail compared to other areas in Bangladesh. The most prevalent helminths were Haemonchus spp. (31.2\%) in small ruminants as reported by other investigators. However the findings varied from some other reports indicating a higher prevalence of $51.7 \%$ in Chittagong and $57.8 \%$ in Rajshahi (Hassan et al., 2011; Nahar et al., 2015). Variation in occurrence of such infection in small ruminants might be due to free living nature and different bionomics of the parasites (Urquhart et al., 1996 and Soulsby et. al., 1982). Prevalence of Oesophagostomum spp. infection in this study was $10.8 \%$ which varied from the findings of Molla and Bandyopadhyay (2016) who recorded prevalence of Oesophagostomum spp. infection as $21.48 \%$ in India. In this study, Oesophagostomum spp. infection rate was low which might be due to the relatively long life cycle and low resistance to desiccation of the pre-infective stages of this genus (Pfukeny et al., 2007). The only cestode identified in this study was Moniezia spp. and the prevalence was $2.1 \%$. Singh et al. (2015) observed $3.1 \%$ infection in India which supported the findings of this study. Lower prevalence of Moniezia spp. might be due to less dissemination of eggs in the faces from the gravid segments (Radostits et al., 1994). The highest prevalence of trematode was Paramphistomum spp. $(28.1 \%)$ and the infection rate of this study varied from the observation of Uddin et al. (2006) and Uddin et al. (1998) who recorded $65.3 \%$ and $56.7 \%$ prevalence in different regions in Bangladesh. Lower prevalence of Paramphistomum spp. infection in this study might be due to unavailability of vector snail, geoclimatic conditions or improved husbandry practices (Alim et al., 2011).EPG count was the highest in case of Moniezia spp. (100-6100) and lowest incase of Trichuris sp. (100).

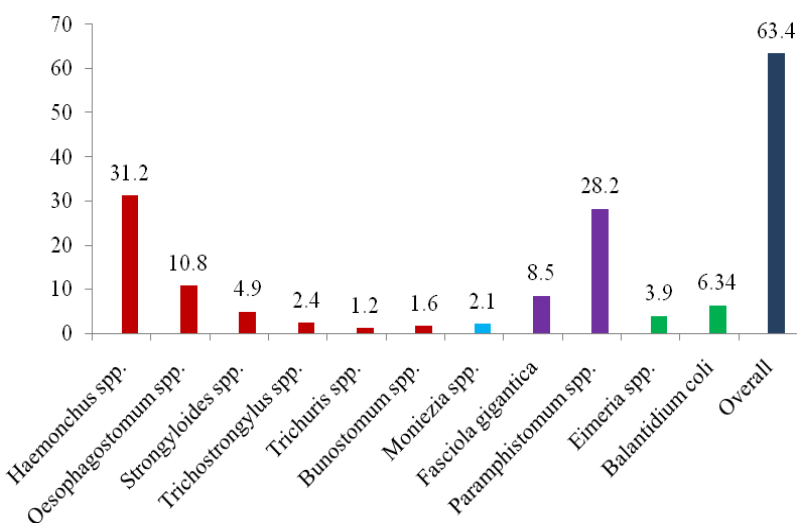

Fig. 1. Overall prevalence (\%) of GI parasites in sheep and goats

Age related prevalence of GI parasites in small ruminants

In the present study, age had a significant effect on the prevalence of gastrointestinal parasitism in small ruminants $(\mathrm{p}<0.05)$.Age-wise analysis exposed higher infection in adult $(65.1 \%)$ than young small ruminants (58.1\%) (Table 1). Biu et al. (2009); Uddin et al. (2006) 
and Soulsby et al. (1982) reported that small ruminants of morethan 2 years of age showed more susceptibility to endoparasitism, which showed consistency with the result of this study. Uddin et al. (2006) also observed that gastrointestinal parasitism was significantly influenced by the age of the small ruminants. Hassan $e t$ al. (2011) also observed age as a risk factor where older small ruminants ( $>24$ months) were more susceptible to gastro-intestinal parasites than younger ones $(<24$ months), which supports the findings of the study.

Sex related prevalence of GI parasites in small ruminants

It was found that, the sex of small ruminants had no significant ( $p>0.05$ ) effect on gastrointestinal parasitism. The infection rate was higher in females $(65.7 \%)$ compared to males (60.1\%) (Table 1).In both males and females, the highest prevalence was observed with
Haemonchus spp., about $31.1 \%$ and $31.0 \%$, respectively. According to Shahiduzzaman et al. (2003), Uddin et al. (2006) and Biu et al. (2009) higher prevalence of parasites occurred in female small ruminants. Likewise, Mazidet al.(2006) also recorded higher prevalence of helminthiasis in female sheep $(100 \%)$ than in male (78.6\%) in Bangladesh. This study was found inconsistent with that of Yeasmin et al. (2015) who reported that male sheep $(81.5 \%)$ were more infected with helminths as compared to female $(72.7 \%)$ in Bangladesh. In this study, variation in occurrence of such parasites in male and female animals might be due to the variation in sample size, lowered resistance of female animals temporary loss of acquired immunity near parturition (Garcia et al.,2007), stress, genetic resistance of host and insufficient/imbalanced feed against higher needs (Raza et al., 2010).

Table 1. Prevalence of GI parasites in small ruminants with related risk factors

\begin{tabular}{|c|c|c|c|c|c|}
\hline \multirow{3}{*}{$\begin{array}{l}\text { Risk factors } \\
\text { Age }\end{array}$} & & Prevalence (\%) & Range & Mean \pm SE & p-value \\
\hline & Young & $61(58.1)$ & $100-300$ & $126.7 \pm 7.0$ & $0.042^{*}$ \\
\hline & Adult & $209(65.1)$ & $100-6100$ & $182.9 \pm 73.1$ & \\
\hline \multirow[t]{2}{*}{ Sex } & Male & $107(60.1)$ & $100-400$ & $119.4 \pm 9.7$ & $0.351^{\mathrm{NS}}$ \\
\hline & Female & $163(65.7)$ & $100-6100$ & $221.8 \pm 113.1$ & \\
\hline Species & $\begin{array}{c}\text { Sheep } \\
\text { Goat }\end{array}$ & $\begin{array}{l}54(60.67) \\
216(64.1)\end{array}$ & $\begin{array}{c}100-200 \\
100-6100\end{array}$ & $\begin{array}{c}112.9 \pm 6.9 \\
176.7 \pm 65.6\end{array}$ & $0.272^{\mathrm{NS}}$ \\
\hline $\begin{array}{l}\text { Body } \\
\text { condition }\end{array}$ & $\begin{array}{l}\text { Poor } \\
\text { Moderate } \\
\text { Good }\end{array}$ & $\begin{array}{c}168(74.7) \\
63(62.4) \\
39(39.0)\end{array}$ & $\begin{array}{c}100-6100 \\
100-300 \\
100-200\end{array}$ & $\begin{array}{c}253.1 \pm 141.1 \\
113.8 \pm 6.9 \\
116.6 \pm 10.3\end{array}$ & $0.021^{*}$ \\
\hline
\end{tabular}

Legend: $\mathrm{SE}=$ Standard error, ${ }^{*} \mathrm{p}<0.05$, statically significant, $\mathrm{NS}=$ Not significant

Species wise prevalence of GI parasites in small ruminants

In this study, it was noted that species did not have significant effects on the prevalence of gastrointestinal parasites $(p>0.05)$. Overall prevalence of gastrointestinal parasitic infections was higher in goats $(64.1 \%)$ and lower in sheep $(60.7 \%)$ (Table 1). The findings of the present study supports the study of Islam and Taimur (2008), Gadahi et al. (2008) and Yadav et al. (2006)who reported that the prevalence of gastrointestinal parasitic infections was higher in goats than in sheep. Variation of such parasitismin goats and sheep might be due to their grazing habits. This also may be due to the gastrointestinal physiology of sheep, or sheep may be genetically more resistant to GI parasites than goats (Islam and Taimur, 2008).

Nutritional status related prevalence of GI parasites in small ruminants

During this study, it was observed that the body condition had significant effects on the prevalence of GIparasites $(\mathrm{p}<0.05)$. Prevalence was relatively higher in goats and sheep with poor body condition (74.7\%) followed by the animals with moderate $(62.4 \%)$ and good body condition $(39.0 \%)$ (Table 1). This finding is consistent with that of Biswas et al. (2014) who reported that parasitic infection is usually higher in animals with poor body condition. The present study also accede with Etter et al. (1999) who reported that in immune compromised animals, fecundity of parasites is usually increased. It appears that malnutrition in animals increases their susceptibility to the parasitic infection. It may also happen that, the animals becoming poor and weak due to any other causes are not able to resist the challenge of infection and subsequently become more weak and lose condition.

\section{Season related prevalence of GI parasites in small ruminants}

The seasonal effect on gastrointestinal parasitism in small ruminants was found significant $(\mathrm{p}<0.05)$ throughout the year. In all seasons (winter, summer and rainy season), small ruminants were infected with gastrointestinal parasites. Seasonal prevalence and intensity was highest in rainy $(72.4 \%)$ followed by the summer $(61.8 \%)$ and winter season $(56.7 \%)$ (Fig. 2 and Fig. 3). The present finding is similar to the previous reports of Yadav et al. (2006) who reported that the higher prevalence was in rainy season $(88.5 \%)$, but contradictory to the report of Biswas et al. (2014) who reported that the higher prevalence was in summer $(84.6 \%)$, followed by rainy season $(83.6 \%)$ and in winter season $(81.2 \%)$ in Bhola district, Bangladesh. The present result varied with the report of Azhar et al. 
(2002) who reported a higher prevalence in spring $(20.0 \%)$ followed by winter $(13.0 \%)$, while the lower $(9.0 \%)$ was recorded during summer in Pakistan. This might be due to the fact of variation in the geographical location of the study areas, season of survey and also the methods of study.

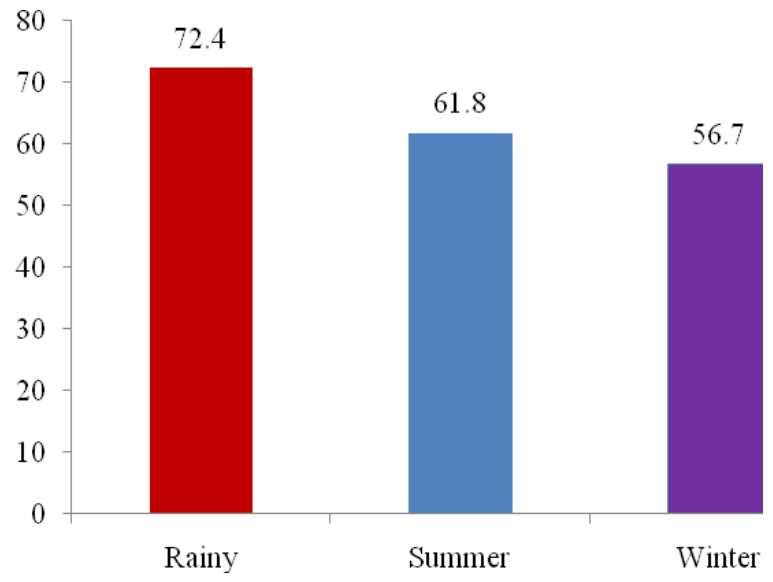

Fig. 2. Seasonal prevalence (\%) of GI parasites in sheep and goat

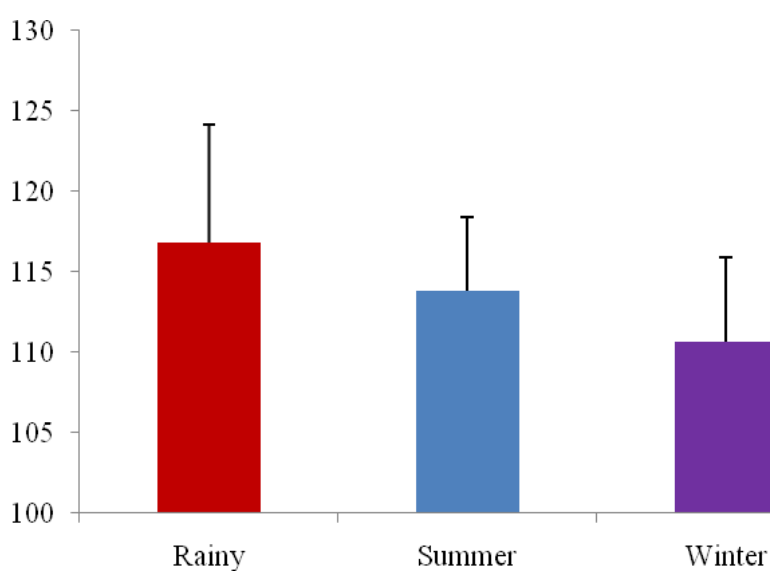

Fig. 3. Seasonal intensity (fecal EPG) of GI parasites in sheep and goats

\section{Conclusion}

The study was conducted to determine the prevalence and risk factors of gastrointestinal parasitic infection in small ruminants. Through coproscopy, an overall $63.4 \%$ infection was detected in sheep and goats. Higher prevalence of gastrointestinal parasites was found in goats compared to sheep indicating possibility of some degree of resistance in sheep. Further study with large sample size and use visceral examination can highlight the actual prevalence of GI parasites. Epidemiological features described during this study will be useful for future researchers to formulate effective control measures.

\section{Acknowledgements}

The authors gratefully express their cordial thanks to Krishi Gobeshona Foundation for the financial supporting of the project (Project No: TF-18 EM/15).

\section{References}

Abede, W. and Esayas, G. 2001.Survey of ovine and caprine gastrointestinal helminthosis in eastern part of Ethiopia during the dry season of the year. Rev de MedVet.,152(5): 379-384.

Alim, M. A. 2011. Prevalence of haemoprotozoan and gastrointestinal parasitic diseases in cattle of Chittagong, Bangladesh. MS Thesis. Department of Pathology and Parasitology, Faculty of Veterinary Medicine, Chittagong Veterinary and Animal Sciences University, Chittagong.

Azhar, M., Chaudhry, S..H., Tanveer, A., and Haji, A.H. 2002. Epidemiology of fasciolosisin buffaloes under different managemental conditions.Vet Arh., 72: 221-228.

Badran, I., Abuamsha, R., Aref, R., Alqisi, W. and Alumor, J. 2012. Prevalence and diversity of gastrointestinal parasites in small ruminants under two different rearing systems in Jenin district of Palestine. An-Najah Univ J Res.,26:1-18

Biswas, H., Dey, A. R., Begum, N. and Das, P.M. 2014. Epidemiological aspects of gastrointestinal parasites in buffaloes in Bhola, Bangladesh.Indian J Anim Sci.,84: 245-250.

Biu, A.A., Maimunatu, A. F., Salamatu,E.T. and Agbadu, 2009.A faecal survey of gastrointestinal parasites of ruminants on the University of Maiduguri Research Farm. Int J Biom and Health Sci., 5: 112-115.

Choubisa, S.L. and Jaroli, V.J. 2013.Gastrointestinal parasitic infection in diverse species of domestic ruminants inhabiting tribal rural areas of southern Rajasthan, India.J Parasit Dis., 37(2): 271-275.

Domingues, L.F., Giglioti, R., Feitosa, K.A., Fantatto, R. R., Rabelo, M.D., Oliveira, M.C.S., Bechara, G.H., Oliveira, G.P., Junior, W.B. and Chagas, A.C.S. 2013. In vitro and in vivo evaluation of the activity of pineapple (Ananascomosus) on Haemonchus contortus in Santa Inês sheep. Vet Parasitol.,197: 263-270.

Etter, E., Chartier, C., Hoste, H. and Borgida, L.P. 1999. The influence of nutrition onthe peri parturient rise in faecal egg counts in dairy goat; Results from a two years study.Rev de Med Vet., 12: 975-980.

Gadahi, J.A., Arshed, M.J., Ali, Q., Javaid, S.B. and Shah, S.I. 2008. Prevalence of gastrointestinal parasites of sheep and goats in and around Rawalpindi and Islamabad, Pakistan.Vet World,2; 51-53.

Garcia, J.A., Rodriguez-Diego, J.G., Torres-Hernandez, G., Mahieu, M., Garcia, E.G. and Gonzalez-Garduno, R. 2007. The epizootiology of ovine gastrointestinal strongyles in province of Matanzas. Small Ruminant Res.,72: 119-126.

Garedaghi, Y., Rezaii-Saber, A.P., Naghizadeh, A. and Nazeri, M. 2011.Survey on prevalence of sheep and goats lungworms in Tabriz abattoir, Iran.Adv Environ Biol., 5.

Hassan, M.M., Hoque, M.A., Islam, S.K.M.A., Khan, S.A., Roy, K. and Banu, Q. 2011. A prevalence of parasites in Black Bengal goats in Chittagong.Int J Livest Prod., 2: 40-42.

Ijaz, M., Khan, M.S., Avais, M., Ashraf, K., Ali, M.M. and Saima, 2008.Infection rate and chemotherapy of various helminths in goats in and around Lahore. PakVet J, 28 : 167-170.

Islam, K.B. and Taimur, M.J.F.A. 2008.Helminthic and protozoan internal parasitic infections in free ranging small ruminants of Bangladesh. Slov Vet Res., 45: 67-72.

Kamaruddin, K.M. 2003.Goat farming as a means of poverty alleviation. In: Proceedings of the BSVER symposium, 
BAU. Bangladesh Society for Veterinary Education \& Research, BSVER Publications No. 25: 26-34.

Mazid, M.A., Bhattacharjee, J., Begum, N. and Rahman, M.H. 2006.Helminth parasites of the digestive system of sheep in Mymensingh, Bangladesh. Bangladesh J Vet Med.,4: 117-122.

Molla, S.H. and Bandyopadhyay P.K. 2016.Prevalence of gastrointestinal parasites in economically important Bonpala sheep in India.IOSR J Agric and Vet Sci., 9 (1): 87-93.

Murthy, G. and Rao, P. 2014. Prevalence of gastro intestinal parasites in ruminants and poultry in Telangana region of Andhra Pradesh.J Parasit Dis., 38(2): 190-192.

Nahar, L., Sarder, M.J.U., Mondal, M.M.H., Faruque, M.O. and Rahman, M., 2015.Prevalence of Haemonchosis of goats at Rajshahi district in Bangladesh. Bangladesh $\mathrm{J}$ Vet Med., 13(1): 29-36.

Pfukenyi,D.M., Mukaratirwa, S. and Monrad, J. 2007. Epidemiological studies of parasitic gastrointestinal nematodes, cestodes and coccidia infections in cattle in the high veld and low veld communal grazing areas of Zimbabwe. Onderstepoort J Vet Res.,74: 129-142.

Poddar, P.R., Begum, N., Alim, M.A., Dey, A.R., Hossain, M.S. and Labony, S.S. 2017. Prevalence of gastrointestinal helminths of sheep in Sherpur, Bangladesh. J Adv Vet and Anim Res.,4: 274-280.

Radostits, O.M., Blood, D.C. and Gay, C.C. 1994: Veterinary Medicine: A text book of disease of cattle, sheep, pigs, goats and horse. 8th edition Baillere Tindall Publication, London. pp. 1171-1179, 1207-1212, 1221-1278.

Rahman, A. 1975.Studies in the diseases of goats in Bangladesh. Mortality of goats under farm and rural conditions. Trop Anim Health Prod., 8: 90.
Raza, A.M., Murtaza, S., Bachaya, H.A., Qayyum, A. and Zaman, M.A. 2010. Point Prevalence of Toxocara vitulorum in large ruminants slaughtered at Multan abattoir. Pak Vet J., 30: $242-244$.

Shahiduzzaman, 2003. Seasonal the occurance of Haemonchus contortus infection in slaughtered Black Bengal in Bangladesh. Bangladesh J Vet Med., 1: 45-48.

Singh, A. K., Das, G., Roy, B., Nath, S., Naresh, R. and Kumar, S. 2015. Prevalence of gastrointestinal parasitic infections in goat of Madhya Pradesh, India.J Parasit Dis., 39(4): 716719 .

Soulsby, E.J.L. 1982. Helminths, Arthropods and Protozoa of Domesticated Animals, 7th edition. Baillere Tindall, London. pp. 707-717, 729-735.

Tariq K., Chishti M. and Ahmad F.2010. Gastrointestinal nematode infections in goats relative to season, host, sex and age from the Kashmir valley.Indian J Helminthol.,84(01):93-97.

Uddin, K.H., Main, M.F. and Taimur, M.J.F.A. 1998. Gastrointestinal helminth infections of goats in Chittagong hill tract area of Bangladesh. Bangladesh JLivest Res., 5: 18-24.

Uddin, M.Z., Farjana, T., Begum, N. and Mondal, M.M.H. 2006. Prevalence of amphistomes in Black Bengal goats in Mymensingh district.Bangladesh J Vet Med., 4: 103-106

Urquhart G.M., Armour J., Duncan J.L., Jennings, F.W. 1996. Veterinary Parasitology, 2nd edition. pp. 242-251.

Yadav, A.and Khajuria, J.K. 2006. Seasonal prevalence of gastrointestinal parasites in sheep and goats of Jammu.J Vet Parasitol.,20: 5971-6157.

Yeasmin, T., Khanum, H. and Zaman, R.F. 2015.Seasonal prevalence of arthropoda and helminth parasites in sheep (Ovisaries) Bangladesh. Bangladesh J Zool., 42:45-55. 